\title{
A Study on the Relationship between University Students' Chinese Writing Proficiency and Their English Writing Proficiency
}

\author{
Xiaoyu Huang (Corresponding author) \\ School of Foreign Languages, Beijing Forestry University \\ Qinhua East Road No. 35, Haidian District, Beijing 100083, P.R. China \\ Tel: 86-10-8230-9560_E-mail: huangxy_1222@yahoo.com.cn \\ Xueying Liang \\ School of Foreign Languages, Beijing Forestry University \\ Qinhua East Road No. 35, Haidian District, Beijing 100083, P.R. China \\ E-mail: violetxueying123@yahoo.com.cn \\ Effie Dracopoulos \\ Department of English and French Language Programs \\ Centre for Continuing Education, McGill University \\ 688 Sherbrooke West, Montreal, Quebec, Canada
}

Tel: 514-398-1201 E-mail: effie.dracopoulos@mcgill.ca

Received: August 26, $2010 \quad$ Accepted: November 18, $2010 \quad$ doi:10.5539/elt.v4n2p55

\begin{abstract}
Up to now, most researchers have been paying attention to the negative transfer of mother tongue to second language writing. Few studies, if any, have touched upon the positive transfer. Therefore, the purpose of this study is to investigate the positive transfer of Chinese to 26 first-year university students' English writing holistically and segmentally in the use of words, grammar, coherence, and content and organization. The result of the Pearson correlation coefficient turned out to be 0.43 at the $5 \%$ significance level, indicating a positive relationship between the Chinese writing and the English writing. The questionnaires have also confirmed the result of the correlation analysis. In particular, the positive transfer of Chinese seems to be more apparent in the content and organization of the English writing, followed by coherence and use of words. Thus, it can be concluded that the positive transfer of mother tongue can facilitate English writing.
\end{abstract}

Keywords: Chinese writing proficiency, Positive transfer, English writing proficiency

\section{Introduction}

The role of mother tongue in second language (L2) writing is a hot topic for discussion in ESL teaching. Much research has been done since the 1980s on the negative effect of mother tongue on second language writing (Connor and McCagg 1983; Edelsky 1982; Krapels 1990); however, few studies, if any, have attached any importance to the positive transfer of mother tongue, particularly of Chinese on English writing. Therefore, it is of great significance to investigate the positive effect of Chinese on English writing for Chinese learners of English as a second language. The significance is straightforward. Firstly as one of the four basic skills for acquiring L2, writing is always regarded as an essential criterion in measuring the linguistic competence of the learner. Secondly, for English teachers, it is necessary to have a clear idea of the elements of the mother tongue that influence English writing to facilitate their teaching. Thirdly, the findings of this research can, hopefully, shed some light on the positive transfer of Chinese writing on English writing and, to some extent, contribute to the large body of literature related to language transfer.

So, in relation to what has been stated above, the objective of the research is to examine the relationship between learners' Chinese writing proficiency and their English writing proficiency through an experiment and the use of questionnaires. It attempts to answer the following two questions:

(1) Is learners' Chinese writing proficiency positively related to their English writing proficiency? In other words, do those learners who have a higher proficiency in Chinese writing also perform better in English writing? 
(2) If the answer is positive, would the learners who have a higher proficiency in Chinese writing also have an advantage in such aspects as use of words, grammar, coherence, and content and organization in their English writing over those who have a lower proficiency in Chinese writing?

Some language teachers and researchers might think that writing proficiency involves both linguistic and metalinguistic knowledge. This research takes both into account. For example, in the process of writing, the learner may consider what to write (content) and how to organize his essay (organization) in either his mother tongue or the target language.

\section{Theoretical Perspectives on Language Transfer}

Language transfer is not a new concept. Early in 1965, Ellis defined "transfer" as the influence of previous task A on task B (1965). Odlin (1989) regards it as "the influence resulting from the similarities and differences between the target language and any other language that has been previously (and perhaps imperfectly) acquired" (p. 27).

However, it was Lado (1957) who first introduced the term "language transfer" to the field of second language acquisition (SLA) because it was believed that SLA was strongly influenced by the learner's mother tongue or first language (L1). Theoretical and empirical research abounded in this field in the late 1940s and early 1950s in both bilingualism and SLA, but disagreement also existed among researchers as to the extent and nature of the influence of the mother tongue. The recognition of the role of L1 experienced ups and downs. It was recognized in the 1950s and 1960s, rejected in the following decade, re-recognized in the 1980s, when it finally gained full acceptance. In essence, the acceptance or rejection of the role of mother tongue has been related to the varying theories of language and language learning, which dominated SLA at different times (Gass and Selinker, 1994).

In fact, the important role of L1 was acknowledged in the 1950s and 1960s under the influence of behaviorism, which contended that the major obstacle to learning was interference from prior knowledge. In other words, previous learning prohibits the learning of new habits. Language acquisition was then viewed as a process of habit-formation and habits were formed through repeated stimulus-response associations, which would become bonded when positively reinforced. SLA was then regarded as a process of overcoming the old habits of the native language in order to acquire the new habits of the target language (Larsen and Michael, 2000). "Errors, according to the theory, were the result of interference from the entrenched habits of the L1" (Ellis, 1994: 39).

Based on the behaviorist learning theory, Contrastive Analysis (CA) enjoyed great popularity at the time, which claimed that "where two languages were similar, positive transfer would occur; where two languages were different, negative transfer, or interference, would result" (Larsen and Michael, 2000: 53). The "difference = difficulty" assumption was, nevertheless, not well supported by research findings.

Then, the 1970s saw a number of attempts to validate the contrastive analysis hypothesis (CAH), but witnessed a downplayed role of L1 in SLA, when behaviorism was under severe attack. Greatly influenced by the Chomskyan framework (1959), the view of learning as the development of a new set of habits gradually gave way to the perspective of language learning as a "creative rule-construction" or rule-formation process, in which rules are learned not simply by imitation, but by actively formulating them on the basis of innate principles as well as on the basis of exposure to the language being learned (Dulay and Burnt, 1973). Furthermore, researchers turned their attention to similarities in the acquisition process among all language learners regardless of native language background.

In the 1980s, scholars and researchers once again began to focus their attention on the role of L1 in SLA, examining it from a cognitive rather than a behaviourist point of view. In fact, looking at the L1 interference from the cognitive perspective began with Selinker (1972). In his formulation of interlanguage theory, Selinker (1972) indentified L1 interference as one factor among many of the cognitive process responsible for SLA. In addition, differing from the traditional notion that errors were signs of unsuccessful learning, the philosophy of Error Analysis regards the learner's errors as unavoidable. Instead, they are evidence of the system of the language the learner is using at a particular point in the process of his learning (Huang, 2005). In other words, the making of errors was not regarded as failure, but as a learner strategy. Corder (1992) suggests that the learner's L1 may facilitate the development process of learning a L2, by helping him to process more rapidly along the universal route when the L1 was similar to the L2. Interference errors result not from negative transfer but from borrowing. That is, when learners experience difficulty in communicating an idea because they lack the necessary resources, they will resort to their L1 to make up the insufficiency. Krashen (1985) thinks that learners may use their L1 to initiate utterances when they do not have sufficient acquired knowledge of the target language for this purpose. Taylor (1975) argues that the use of L1 is merely one manifestation of a very general psychological process - that of relying on prior knowledge to facilitate new learning. Thus, the importance of L1 in SLA was re-recognized. 
Meanwhile, Cummins (1980, 1981, 1983) advanced a model of bilingual proficiency known as "common underlying proficiency" (CUP), which intends to explain the relationship between a learner's linguistic competence in the mother tongue and the linguistic competence in the second language (L2) in bilingual education. The core of the theory is that in the process of learning a language a child picks up a set of skills and metalinguistic knowledge which can be used when learning another language. According to Cummins (2000), conceptual knowledge developed in one language can help to make input in the other language comprehensible. In other words, knowledge gained through experience in L1 can theoretically facilitate the development of L2.

Cummins (1984) also argues that the learner's cognitive ability of the mother tongue and that of the second language is interdependent. In the course of his second language acquisition, the learner's cognitive ability of the mother tongue plays the role of the cognitive base for his second language development. In other words, the learner's proficiency of reading and writing in the mother tongue can anticipate his/her cognitive ability of the second language in the future. Bilingualism and continued development in the first language enhances metalinguistic skills and development in proficiency in the second language.

In sum, although research on language transfer fell out of favor for a time, it has been a central issue in applied linguistics, second language acquisition and language teaching for at least a century (Odlin, 1989). As Gass and Selinker (1994) puts it, "There is now overwhelming evidence that language transfer is indeed a real and central phenomenon that must be considered in any full account of the second language acquisition "(p.7) .

\section{Research on Transfer and L2 Proficiency}

A number of studies have been carried out on transfer and L2 proficiency. Taylor (1975), for example, studied the relationship between learners' L1 and L2 proficiency levels. The subjects of his study were native speakers of Spanish, whose target language was English. They were asked to translate eight sentences from Spanish into English. An analysis of the subjects' errors showed that elementary level learners made significantly more transfer errors than intermediate learners. This, according to Taylor (1975), was so because lower level learners lacked knowledge of the target language system and had to resort to their L1 in the L2 production. So, he concluded that as learners' level of L2 proficiency increases, they will rely more on their L2 knowledge and transfer less from their L1. Taylor's (1975) conclusion was justified by Fathman and LoCoco (1989) who examined the acquisition of English linguistic forms that indicate possession and negation. Chen (1992) as well finds a relationship between learner's L1 and L2 proficiency level.

However, different opinions also exist in the field of SLA. Klein (1986), for instance, found out that the number of transfer errors increases with an increased level of proficiency. He noted that at the elementary level learners cannot apply specific rules of the target language because they do not know them; the learners cannot transfer the rules from their native language to their target language because their L1 structures are not reinforced by the corresponding L2 structures.

The different results of Klein's (1986) research were expected because for each study the languages, namely the native language and the target language, and related linguistic subsystems selected for analysis might be different. As a result, the transfer processes as well as the findings might be different.

\section{Research on the Influence of L1 on L2 Writing}

Research has also been conducted on the influence of L1 on L2 writing. For a long time it has generally been assumed that L1 writing and L2 writing are, for whatever purposes, the same. This assumption is based on the fact that L1 and L2 are similar in their broad outlines - both L1 and L2 writers go through almost the same composing process: planning, writing and revising, to develop their ideas and find appropriate rhetorical and linguistic means to express them. However, an important difference between L1 and L2 writing processes is that L2 writing involves the use of both L1 and L2 linguistically and cognitively. In addition to the fact that cognitive and literacy skills established in the mother tongue will transfer across languages (Cummins, 1983), "L2 writing is strategically, rhetorically, and linguistically different in important ways from L1 writing" (Silva, 1993: 669).

In spite of all the similarities and differences between L1 and L2 writing, research showed that there was a common underlying proficiency in writing ability across languages (Edelsky, 1982). Research also indicated that L1 writing expertise plays an important role in L2 writing (Sasaki \& Hirose, 1996).

The influence of L1 on L2 writing has been studied at both product and process levels. In terms of product, studies of compositions by L2 writers focus mainly on contrastive rhetoric by analyzing the transfer of L1 rhetorical patterns into L2 writing (Kaplan, 1966). This cross-linguistic influence has been accounted for not only in terms of cultural differences, but also more recently in reference to developmental and cognitive factors. Since the 1980s, given the impetus by L1 studies, a great deal of research on L2 writing has focused on the process because the 
product-oriented research cannot reveal the use of $\mathrm{L} 1$ in the whole process of L2 writing. Apart from that, a renewed attention has also been directed to the use of L1 in the process of composing in a second language after a long-time criticism of L1 use by L2 learners in the process.

Early studies on language transfer mainly focused on errors committed by learners. However, research results on Error Analysis differed widely with regard to the proportion of errors transferred from L1 to L2, ranging from merely 3 percent in the study of the corpus of Spanish-speaking learners' of English (Dulay \& Burt, 1973) to 51 percent in the research of adult Chinese-speaking learners of English (Tran-Chi-Chau, 1975) . This could be explained by such factors as the type of language sampled, the language proficiency level and the learners' ages (Ellis, 1989).

Empirical studies to investigate L1 influence on the learner's L2 were initiated by Newser (1981) who reported the use of mother tongue in the speech of some immigrant workers in the United States. Then, Connor and McCagg (1983) studied transfer in learners'compositions and Biskup (1992) analysed transfer in the learner's use of collocations.

In her study of the role of L1 in L2 writing, Lay (1982) found out that her Chinese subjects tended to switch to thinking in their first language when writing about a topic related to their first language background. In this case, their first language served as an aid instead of hindrance to writing. So, it turned out that more native language switches in L2 writing process resulted in better quality in the written products in terms of expression of ideas, organization and details (Lay, 1982). Krapels (1990) also points out that the use of L1 for thinking is a fairly common strategy among L2 writers.

In addition, Cumming (1989) attempted to show when and how L1 was used by writers at different levels in L2 writing. In his study, inexpert French ESL writers were found to use their first language to generate content, regardless of the language of the topic. In contrast, expert writers used translation not only to generate content but to verify appropriate word choice, for they knew that the use of their first language would enhance their writing in English.

More recently, Guo and Liu (1997) studied the process of English picture compositions of L2 students from different grades which represented different English proficiency levels through Think Aloud (TA). The quantitative result showed a large amount of L1 use, 55\% on average. The qualitative result indicated three functions of the L1 thinking: (1) L1 as intermediary language in logic reasoning processing; (2) formal monitoring in target language output; and (3) mutual retrieval of the word conception and the target language (Guo \& Liu, 1997). Later, Wen and Guo (1998) conducted further research on the topic and found that the students with higher scores for the picture composition used L1 far less than the students with lower scores. They also reported five functions of the mother tongue: (1) transformation; (2) confirmation; (3) generating ideas; (4) retrieving L2 forms; and (5) controlling the writing procedures (Wen \& Guo, 1998).

As to how L1 use is affected by L2 proficiency levels and writing tasks, Wang and Wen (2004) investigated the compositions of 16 English major students and found that those with a lower English proficiency level tended to translate directly from L1 into L2 during their L2 writing process, whereas the advanced learners seemed to use L1 strategically for idea-generating, monitoring, and lexical-searching purposes. They also found that more L1 was used in narrative writing tasks than in argumentative writing tasks (ibid).

Although these studies have endeavoured to find the influence of native language on second language writing in various ways, it seems that few studies, if any, have touched upon the relationship between the writing proficiency of the Chinese language and that of the English language. In other words, whether learners' L1 writing proficiency is related to their L2 writing proficiency is still a question that needs to be answered. Given the need for a more thorough understanding of the role of L1 in L2 writing, the current study was an attempt to provide an answer to this question. It is presumed that if the learner has a good command of his first language, he will acquire the second language more easily. By analogy, this also holds true with respect to writing in both languages.

\section{Research Methods}

In order to investigate the positive transfer of university students' Chinese writing to English writing, two research methods were adopted in this study: a correlation analysis of the students' English and Chinese writing and the use of questionnaires.

\subsection{The Subjects}

The subjects of the experiment were 26 non-English major sophomores in Zhongyuan University of Technology, Henan Province. All the participants were in the same class so as to minimize variables since they had the same teaching background. These students majored in Business Management, and they took English Extensive Reading 
classes as a required course. Before they entered university, they had received a formal English education for eight years on average. Since they were having training classes in preparation for the College English Test Band Four (CET 4) in their normal English classes, they had a high motivation to participate in the experiment, which was considered beneficial to their test.

\subsection{Procedures}

The same topic was used for both the English and the Chinese writing in the experiment for comparison purposes. The selection of the topic took two variables into consideration: (1) cultural neutrality of the topic, and (2) students' familiarity with the topic. The type of writing was expository, so no specific background information was required. In the meantime, the level of cognitive demand in the two writings was considered equivalent. Before the topic (taken from the independent writing section of the TOEFL iBT) was used, the researchers talked with the students' English teacher to make sure that the topic was new to them. The topic of the TOEFL writing was taken out of three considerations: (1) the validity of the writing, (2) the attractiveness of the TOEFL writing topics to elicit the best production, and (3) the rating scale available for use.

The subjects were required to complete two writing tasks in class. The English writing task was carried out three weeks before the Chinese writing task to avoid memory effect and to minimize the possibility of translating from Chinese into English. Before the two writing tasks, the students were given some training to ensure that they understood the requirements of the tasks and to become familiarized with the TOEFL independent writing. The tasks were implemented in the subjects' English Extensive Reading class so that they could treat them seriously. A total of 30 minutes was allowed for each writing task. Considering that the students' time was occupied by the Chinese writing task, this was compensated by another hour under mutual agreement in which the researchers provided feedback about their writings.

Again for comparison purposes, two versions of a questionnaire, one in English and one in Chinese, were designed to collect information about the subjects' English and Chinese writing processes, including their writing habits and details about their writing processes concerning choice of words, use of grammar, essay organization, and so on. The questionnaire contained three types of questions: multiple-choice questions, scaled questions and open-ended questions for the collection of in-depth information and ideas. Each time, the questionnaires were distributed to the subjects immediately after they had completed their compositions. To avoid misunderstanding, the researchers explained each questionnaire beforehand in Chinese. Then, the questionnaires were collected immediately after they had been completed so as to guarantee maximum retrieval.

\subsection{Data Collection}

The data came from both the writings and the questionnaire. For the English writing, two raters were asked to score the essays using the TOEFL rating scale for independent writing. Both raters had more than three years of teaching experience in English writing. As for the Chinese writing, two experienced Chinese teachers in a senior high school were asked to score the essays according to the rating scale for Chinese compositions of the National University Entrance Examination. (Note 1) Both the students' English and Chinese essays were assessed holistically and segmentally for use of words, grammar, coherence, and content and organization. Each student's average of the two raters' scores from each group of teachers was his/her final score. The use of average scores for each of the students' writings was to increase the reliability of the essay evaluation (Heaton, 2000: 164; Woods, et al. 2000: 216) and to minimize the inevitable errors in the experiment. Both groups of raters had come to an agreement on the rating scales through discussion.

For the two versions of the questionnaire, the multiple-choice questions were designed basically for personal background information. The scaled questions were the main part of the questionnaire consisting of four sections concerning use of words, grammar, coherence, and content and organization. Five alternatives were given to each question and data from all items were aggregated and categorized again into the four areas for final analysis. The open-ended questions made it possible to elicit opinions and detailed information from the subjects.

\section{Results and Discussion}

\subsection{Results and Discussion for the Writings}

The Pearson product-moment correlation coefficient was used to test the degree of correlation between the students' English writing proficiency and their Chinese writing proficiency. The results are presented in Table 1.

From the table, it can be seen that, holistically, the correlation between the students' English writing and their Chinese writing is 0.43 at the $5 \%$ significance level. This means that there is a positive correlation between the two modes of writing. In terms of the other four aspects, the correlation coefficient for coherence in the two modes of writing is 0.37 at the $10 \%$ significance level, indicating that to some extent those students who were good at making 
their essays coherent in the Chinese writing might also be good at doing so in their English writing. In addition, the correlation coefficient for content and organization is 0.53 at the $10 \%$ significance level, which proves that the students who were strong at expressing and organizing their ideas well in their Chinese writing might also have an advantage over the others in these aspects in their English writing. Therefore, it can be concluded that Chinese might be helpful to the students' English writing as a whole, and in such aspects as coherence, and content and organization.

\subsection{Results and Discussion for the Questionnaires}

In order to confirm the results obtained from the correlation analysis, data were collected from the questionnaires and then analysed using $\chi^{2}$ test to compare the answers to the two versions of the questionnaire. Before the analysis, it was hypothesised that there was no difference between the answers of the two questionnaires with regard to the English writing and the Chinese writing in the aspects of use of words, grammar, coherence, and content and organization. The results for the hypothesis testing are presented in the following contingency tables (2-5):

\subsubsection{Section 1 of the Questionnaires Concerning Use of Words}

e.g. You pay attention to choosing appropriate words or phrases so as to state ideas clearly.
A. Very often
B. Often
C. Sometimes
D. Occasionally
E. Almost never

By consulting the Chi-squared distribution table, it was found that with $4 \mathrm{df}$ the critical value at the $5 \%$ level is 9.49 . However, the total deviance of 3.03 in Table 2 shows that it is not significant at the $5 \%$ level. So, we cannot reject the hypothesis that there is no difference between the answers to the two questionnaires with regard to the English writing and Chinese writing in use of words. In other words, the subjects paid similar attention to use of words in their English and Chinese writing.

\subsubsection{Section 2 of the Questionnaires Concerning Grammar}

e.g. You pay great attention to grammar while you are writing.
A. Very Often
B. Often
C. Sometimes
D. Occasionally
E. Almost never

From Table 3, it can be seen that the total deviance for grammar is 11.03 , which is significant at the $5 \%$ level. So, we can reject the hypothesis that there is no difference between the answers to the two questionnaires with regard to the English writing and Chinese writing in grammar. This means that in the process of writing in English and writing in Chinese, the students paid different attention to grammar.

\subsubsection{Section 3 of the Questionnaires Concerning Coherence}

e.g. You pay attention to using conjunctions to make your composition coherent.
A. Very often
B. Often
C. Sometimes
D. Occasionally
E. Almost never

Table 4 shows that the total deviance for coherence is 3.78 at the $5 \%$ level, so it is statistically non-significant. Thus, the hypothesis that there is no difference between the answers to the two questionnaires with regard to the English writing and Chinese writing in coherence cannot be rejected, indicating that the extent to which the students paid attention to coherence in their Chinese writing is similar to the attention they paid to coherence in their English writing.

\subsubsection{Section 4 of the Questionnaires Concerning Content and Organization}

e.g. While writing, you pay attention to the content and organization of the composition.
A. Very often
B. Often
C. Sometimes
D. Occasionally
E. Almost never

Again the total deviance of 1.58 for content and organization is non-significant at the $5 \%$ level, as is indicated by Table 5. Accordingly, one cannot reject the hypothesis that there is no difference between the answers to the two questionnaires with regard to the English writing and Chinese writing in content and organization, meaning that in the processes of writing, if the students paid attention to content and organization in their Chinese writing, they would also do so in their English writing.

In addition, in the questionnaire for the English writing, for the question of whether the subjects tended to use Chinese when they got blocked in the process of English writing, $42.3 \%$ of the subjects answered "occasionally" and $19.2 \%$ said "sometimes", which means that more than half of the subjects tried to avoid using Chinese directly in the process of English writing even when they encountered difficulties.

As for the question of whether the subjects were likely to think in Chinese while finding more appropriate English words and expressions, $38.5 \%, 26.9 \%$ and $23.1 \%$ of the subjects answered "often", "sometimes" and "occasionally" respectively, which indicates that Chinese thinking was a great help to students in expressing their ideas. 
When asked whether they translated from Chinese into English in the process of the English writing, $76.9 \%$ of the subjects admitted that it was inevitable to do so. As for the amount of translation, $61.5 \%$ of the subjects reported "at least $50 \%$ ".

With regard to the awareness of the differences between English writing and Chinese writing, $30.7 \%$ of the subjects reported that they "often" or "sometimes" pay attention to the differences. In other words, although they sometimes think in Chinese, they try to write what they have thought following English rules.

The students also think that whether it is writing in English or Chinese, finding an appropriate word to express ideas clearly is the most difficult. Using complex grammatical structures and organizing an essay well are not easy tasks, either. Comparatively speaking, developing ideas in depth is not so difficult in Chinese as it is in English.

\subsection{Summary of Correlation Analysis and Questionnaire}

From the Pearson product-moment correlation coefficient, it can be seen that the correlation coefficient is 0.43 at the $5 \%$ significance level, which indicates holistically a moderate relationship between the students' English writing proficiency and their Chinese writing proficiency. Specifically, positive transfer of Chinese to English occurs more obviously in content and organization in the English writing. However, in the other two aspects, use of words and coherence, the correlation between Chinese writing and English writing is low. In addition, the correlation between the Chinese writing and the English writing is negative in grammar, indicating a negative transfer of the Chinese language to the English language.

The results of the questionnaires completed after the students finished their English writing and Chinese writing have confirmed the results from the correlation analysis. Furthermore, the questionnaires helped provide additional information to explain the reasons behind the results.

Firstly, the subjects tended to use Chinese thinking to organize and elaborate ideas when they encountered difficulties in the process of English writing, since the students were more familiar with their native language. This is why $76.9 \%$ of the subjects admitted that Chinese translation was inevitable in the process of English writing. In the open-ended question of whether Chinese is helpful in the process of English writing and in which aspect it is helpful, developing and organizing ideas and choosing appropriate words rank among the top two reasons. This also explains the comparatively high correlation coefficient in content and organization.

Secondly, it is worth noting that the Pearson correlation coefficient of the Chinese writing and the English writing in coherence is 0.37 at the $10 \%$ significance level, which is confirmed by the subjects' answers to the very question in the questionnaire.

The reason might be that the students' stronger ability in expressing themselves in Chinese helps them to make their English writing more coherent subconsciously. As a result, those students whose Chinese writing was more fluent also performed better in their English writing in coherence. Furthermore, since the subjects were noticeably aware of the similarities and differences between writing in English and writing in Chinese, they might consciously make efforts to avoid errors caused by the differences, and make use of the similarities between Chinese and English to facilitate their L2 writing.

Finally, the fact that Pearson product-moment correlation coefficient for grammar is negative (-0.11) shows that Chinese grammar might have a negative influence on the students' English writing since they are two different linguistic systems. This has also been confirmed by a multiple-choice question in the questionnaire, in which the students were asked in which aspect they think Chinese is no help in the process of English writing; $55.3 \%$ of the subjects chose the alternative "Using correct grammar" as their first choice.

\section{Conclusion}

From the results of the English and Chinese writings and the questionnaires discussed above, we can now come to the following conclusions. First, on the whole, the subjects' Chinese writing proficiency is positively related to their English writing proficiency. In other words, those students who have a higher proficiency in their Chinese writing also perform better in their English writing. So, this answers our first research question.

Second, and specifically, there is also a positive correlation between Chinese writing and English writing with regard to content and organization, coherence and use of words. This means that the learners' mother tongue might be helpful to their English writing in developing and organizing ideas. This result is consistent with the research results of Lay (1982) and Krapels (1990), which indicate that L1 is most helpful in thinking, organization and expression of ideas. The mother tongue might also be useful in choosing appropriate English equivalents, and making the learners' essays coherent, although this might cause some other problems, such as errors due to the two different linguistic systems. Moreover, the Pearson correlation coefficient for grammar is negative, which was 
supported by the answers to the questionnaire that Chinese grammar is the least helpful to the learners' English writing. This was, in fact, expected since Chinese and English have totally different grammatical structures. In spite of that, the results have also helped to answer our second research question.

In brief, all our hypotheses have been supported by the data in this research, as evidenced by the correlation and questionnaire analyses presented.

Apart from that, the findings of this study can, hopefully, shed some light on the implications for L2 teaching in several ways. Firstly, teachers should be aware of the positive role of Chinese in English writing and take advantage of Chinese in teaching English writing, while taking into account the negative effect of L1 on L2. In this sense, appropriate guidance is necessary for students. Secondly, it is worthwhile to pay attention to the similarities of Chinese and English writing in expressing and organizing ideas and encourage students to apply the writing techniques they have learned in Chinese writing to English writing. In sum, making use of the positive transfer of the Chinese language and avoiding the negative transfer is beneficial to the improvement of learners' English writing.

The authors would like to take this opportunity to thank the raters of the compositions and the participants for their support for this research.

\section{References}

Biskup, D. (1992). L1 influence on learner's readings of English collocations: a Polish/German empirical study. In P. J. L. Amaud \& H. Bejoint (Eds): Vocabulary and Applied Linguistics. Houndmills: Macmillan. pp. 85-93.

Chen,H. C. (1992). Lexical processing in bilingual speakers. In R. J. Harris (Ed.) Cognitive Processing in Bilinguals. New York: Elsevier Science Publishers. pp. 253-264.

Chomsky, N. (1959). Reviews of verbal behavior by B. F. Skinner. Language, 35, $26-58$.

Connor, U. \& McCagg, P. (1983). Cross-cultural differences and perceived quality of written paraphrases of English expository prose. Applied Linguistics, 4, 259-268.

Comming, A. (1989) Writing expertise and second-language proficiency. Language Learning, 42, 157-182.

Cummins, J. (1980). The entry and exit fallacy in bilingual education. NABE Journal , 4, 25-60.

Cummins, J. (1981). The role of primary language development in promoting educational success for language minority students. In California State Department of Education (Ed.) Schooling and Language Minority Students: A Theoretical Framework. Los Angeles: Evaluation, Dissemination and Assessment Center , California State University. pp.3-49

Cummins, J. (1983). Language proficiency and academic achievement. In J.W. Oller (Ed.) Issues in language testing research. Rowley, Mass.: Newbury House. pp.108-130.

Commins, J. (1984). Bilingualism and Special Education: Issues in Assessment and Pedagogy. Clevedon, England: Multilingual Matters. (Co-published in USA by College-Hill Press). (ISBN: 0-905028-14-7 [hb]; 0-905028-13-9 $[\mathrm{pb}])$.

Cummins, J. (2000). Language, Power and Pedgogy: Bilingual Children in the Crossfire. Clevedon: Multilingual Matters.

Corder, S. P. (1992). A role for the mother tongue. In S. Gass \& L. Selinker (Eds.) Language Transfer in Language Learning. Amsterdam: John Benjamins Publishing Co. pp.18-31.

Dulay, H. \& Burt, M. (1973). Should we teach children syntax? Language Learning, 23, 245-258.

Edelsky, C. (1982). Writing in a bilingual program: The relation of L1 and L2 texts. TESOL Quarterly, 16, 211-228.

Ellis, R. (1965). Understanding Second Language Acquisition. Oxford: Oxford University Press.

Ellis, R. (1989). The Study of Second Language Acquisition. Shanghai: Foreign Language Education Press.

Ellis. R. (1994). The Study of Second Language Acquisition. Oxford: Oxford University Press.

Fathman, A. \& LoCoco, V. (1989). Word order contrasts and production in three target languages. In H. Dechert \& M. Raupach (Eds.) Transfer in Language Production. Norwood, NY: Alblex. pp.159-170.

Gass, S. \& Selinker. L. (Eds.) (1994). Language Transfer in Language Learning. Rowley, MA: Newbury House.

Guo, Ch.J. \& Liu, F. (1997). The influence of mother tongue in foreign language writing. Modern Foreign Language, 4, 30-38. (in Chinese).

Heaton, J. B. (2000). Writing English Language Tests. Beijing: Foreign Language Teaching and Research Press. 
Kaplan, R.B. (1966). Cultural thought patterns in interlanguage education. Language Learning, 16, 1-20.

Klein, W. (1986). Second Language Acquisition. New York: Cambridge University Press.

Krapels, A. R. (1990). An overview of second language writing process research. In B. Kroll (Ed) Second Language Writing: Research Insights for the Classroom. New York: Cambridge University Press. pp. 37-56.

Krashen, S. (1985). The Input Hypothesis: Issues and Implications. New York: Longman.

Lay, N. (1982) Composing process of adult ESL learners: A case study. TESOL Quarterly, 16, 406-407.

Lado, R. (1957). Linguistics Across Cultures: Applied Linguistics for Language Teachers. Ann Arbor: University of Michigan Press.

Larsen-Freemen, D. \& Michael, H. L. (2000). An Introduction to Second Language Acquisition. Beijing: Foreign Language Teaching and Research Press.

Newser, W. (1981). Approximative variation and second language acquisition theory. Applied Linguistics, II(1), 150-168.

Odlin, T. (1989). Language Transfer: Cross-linguistic Influences in Language Learning. New York: Cambridge University Press.

Sasaki, M. \& Hirose, K. (1996). Explanatory variables for EFL students' expository writing. Language Learning, 46, 137-174.

Selinker, L. (1972). 'Interlanguage' International Review of Applied Linguistics 10: 209-231.

Silva, T. (1993). Toward an understanding of the distinct nature of L2 writing: ESL research and its implications. TESOL Quarterly, 27(4), 657-677.

Taylor, B. (1975). The use of overgeneralization and transfer learning strategies by elementary and intermediate students of ESL", Language Learning, 25, 73-107.

Tran-Chi-Chau. (1975). Error and explanations. Applied Linguistics, 7, 144-166.

Wang, L.\& Wen, Q. (2004). Transference of mother tongue proficiency to second language writing: the methodology and Path Analysis of crosslanguage. Foreign Language Teaching and Research, 3, 205-212.(in Chinese).

Wen, Q. \& Guo, Ch. J. (1998). The relationship between thinking in L1 and L2 writing ability: A study of the process of English picture composition by senior middle school students. Modern Foreign Language, 4, 47-56. (in Chinese).

Woods, A., Fletcher, P., \& Hughes, A. (2000). Statistics in Language Studies. Beijing: Foreign Language Teaching and Research Press.

Huang, X. (2005). Multilevel analysis of Chinese EFL learners' errors in their writing,,Teaching English in China, 5: 24-29.

\section{Note}

Note 1. The use of the two different rating scales would not affect the research results since it was in fact not a comparison of two sets of data but just a correlation analysis of the data sets.

Table 1. The Correlation Coefficients of Students' English Writing and Chinese Writing

\begin{tabular}{|c|c|c|c|c|c|}
\hline Chinese writing & Holistic & Use of words & Grammar & Coherence & $\begin{array}{l}\text { Content and } \\
\text { organization }\end{array}$ \\
\hline Holistic & $0.43 *$ & & & & \\
\hline Use of words & & 0.32 & & & \\
\hline Grammar & & & -0.11 & & \\
\hline Coherence & & & & $0.37^{* *}$ & \\
\hline Content and organization & & & & & $0.53 * *$ \\
\hline
\end{tabular}

Note: *Correlation is significant at the $5 \%$ level. ** Correlation is significant at the $10 \%$ level. 
Table 2. Results for Answers in 'Use of Words'
(a) Observed frequencies

The number of students choosing each alternative

\begin{tabular}{|c|c|c|c|c|c|c|}
\hline & & B & $\mathrm{C}$ & D & E & Rowtotal \\
\hline Q A & 5 & 8 & 8 & 4 & 1 & 26 \\
\hline Q B & 1 & 9 & 10 & 5 & 1 & 26 \\
\hline Column total & 6 & 17 & & ste & & 52 \\
\hline
\end{tabular}

(b) Expected frequencies: (row total $) \times($ column total $) \div($ grand total $)$

The number of students choosing each alternative

\begin{tabular}{lllllll} 
& $\mathrm{A}$ & $\mathrm{B}$ & $\mathrm{C}$ & $\mathrm{D}$ & $\mathrm{E}$ & Rowtotal \\
\hline Q A & 3 & 8.5 & 9 & 4.5 & 1 & 26 \\
Q B & 3 & 8.5 & 9 & 4.5 & 1 & 26 \\
Column total & 6 & 17 & 18 & 9 & 2 & 52
\end{tabular}

(c) Deviances: (observed - expected) $2 \div$ expected

The number of students choosing each alternative

\begin{tabular}{lllllll} 
& A & B & C & D & E \\
\hline Q A & 1.33 & 0.03 & 0.11 & 0.06 & 0 \\
Q B & 1.33 & 0.03 & 0.11 & 0.06 & 0
\end{tabular}

Total deviance $=3.03 \mathrm{df}=4$

Note: Q A= Questionnaire A, i.e. the English version, Q B = Questionnaire B, i.e. the Chinese version

Table 3. Results for Answers in 'Grammar'

(a) Observed frequencies

The number of students choosing each alternative

\begin{tabular}{lcccccc} 
& A & B & C & D & E & Rowtotal \\
\hline Q A & 4 & 5 & 15 & 1 & 1 & 26 \\
Q B & 5 & 5 & 5 & 10 & 1 & 26 \\
Column total & 9 & 10 & 20 & 11 & 2 & 52
\end{tabular}

(b) Expected frequencies: (row total $) \times($ column total $) \div($ grand total $)$

The number of students choosing each alternative

\begin{tabular}{lccccccc} 
& $\mathrm{A}$ & $\mathrm{B}$ & $\mathrm{C}$ & $\mathrm{D}$ & & E & Rowtotal \\
\hline Q A & 4.5 & 5 & 10 & 5.5 & 1 & 26 \\
Q B & 4.5 & 5 & 10 & 5.5 & 1 & 26 \\
Column total & 9 & 10 & 20 & 11 & 2 & 52
\end{tabular}

(c) Deviances: (observed - expected) $2 \div$ expected

The number of students choosing each alternative

\begin{tabular}{llllll} 
& A & B & C & D & E \\
\hline Q A & 0.06 & 0 & 2.5 & 2.23 & 0 \\
Q B & 0.06 & 0 & 2.5 & 3.68 & 0
\end{tabular}

Total deviance $=11.03 \quad \mathrm{df}=4$

Note: Q A= Questionnaire A, i.e. the English version, Q B = Questionnaire B, i.e. the Chinese version 
Table 4. Results for Answers in 'Coherence'

\begin{tabular}{|c|c|c|c|c|c|c|}
\hline \multicolumn{7}{|c|}{ (a) Observed frequencies } \\
\hline \multicolumn{7}{|c|}{ The number of students choosing each alternative } \\
\hline & A & $\mathrm{B}$ & $\mathrm{C}$ & $\mathrm{D}$ & $\mathrm{E}$ & Rowtotal \\
\hline Q A & 3 & 7 & 10 & 4 & 2 & 26 \\
\hline Q B & 2 & 11 & 11 & 2 & 0 & 26 \\
\hline Column total & 5 & 18 & 21 & 6 & 2 & 52 \\
\hline
\end{tabular}

(b) Expected frequencies: (row total $) \times($ column total $) \div($ grand total $)$

The number of students choosing each alternative

\begin{tabular}{lcccccc} 
& $\mathrm{A}$ & $\mathrm{B}$ & $\mathrm{C}$ & $\mathrm{D}$ & $\mathrm{E}$ & Rowtotal \\
\hline Q A & 2.5 & 9 & 10.5 & 3 & 1 & 26 \\
Q B & 2.5 & 9 & 10.5 & 3 & 1 & 26 \\
Column total & 5 & 18 & 21 & 6 & 2 & 52
\end{tabular}

(c) Deviances: (observed - expected) $2 \div$ expected

The number of students choosing each alternative

\begin{tabular}{lccccc} 
& A & B & C & D & E \\
\hline Q A & 0.1 & 0.44 & 0.024 & 0.33 & 1 \\
Q B & 0.1 & 0.44 & 0.024 & 0.33 & 1
\end{tabular}

Total deviance $=3.78 \quad \mathrm{df}=4$

Note: Q A= Questionnaire A, i.e. the English version, Q B = Questionnaire B, i.e. the Chinese version

Table 5. Results for Answers in 'Content and Organization'

(a) Observed frequencies

\begin{tabular}{|c|c|c|c|c|c|c|}
\hline \\
\hline & A & B & C & $\mathrm{D}$ & $\mathrm{E}$ & Rowtotal \\
\hline Q A & 5 & 12 & 5 & 2 & 2 & 26 \\
\hline Q B & 3 & 11 & 7 & 4 & 1 & 26 \\
\hline Column total & 8 & 23 & 12 & 6 & 3 & 52 \\
\hline
\end{tabular}

(b) Expected frequencies: (row total $) \times($ column total $) \div($ grand total $)$

The number of students choosing each alternative

\begin{tabular}{lcccccc} 
& $\mathrm{A}$ & $\mathrm{B}$ & $\mathrm{C}$ & $\mathrm{D}$ & $\mathrm{E}$ & Rowtotal \\
\hline Q A & 0.25 & 11.5 & 6 & 3 & 1.5 & 26 \\
Q B & 0.25 & 11.5 & 6 & 3 & 1.5 & 26 \\
Column total & 0.5 & 23 & 12 & 6 & 3 & 52
\end{tabular}

(c) Deviances: (observed - expected) $2 \div$ expected

The number of students choosing each alternative

\begin{tabular}{|c|c|c|c|c|c|}
\hline & A & B & $\mathrm{C}$ & $\mathrm{D}$ & E \\
\hline $\mathrm{QA}$ & 0.1 & 0.02 & 0.17 & 0.33 & 0.17 \\
\hline Q B & 0.1 & 0.02 & 0.17 & 0.33 & 0.17 \\
\hline \multicolumn{6}{|c|}{$\mathrm{df}=4$} \\
\hline
\end{tabular}

Note: Q A= Questionnaire A, i.e. the English version, Q B = Questionnaire B, i.e. the Chinese version 